\title{
Leadership behaviour that facilitates shared leadership emergence in internationally dispersed non-formal teams
}

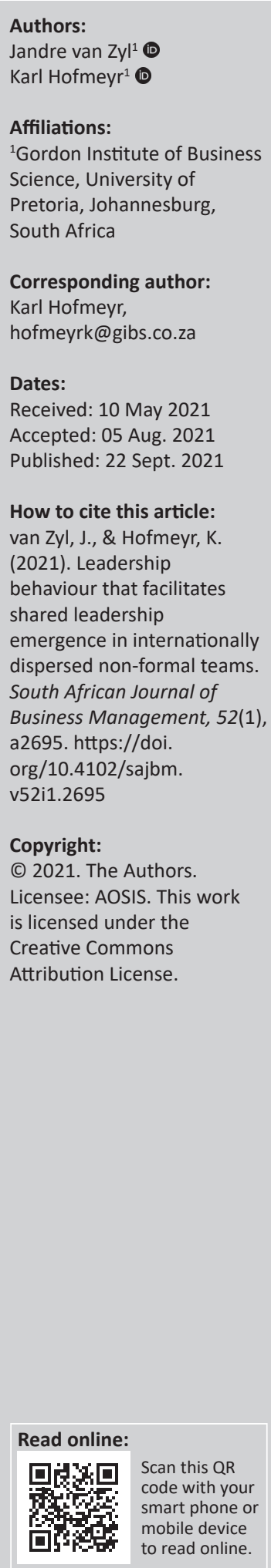

Purpose: Globalisation and the increased complexity of organisations create the need for alternative leadership approaches that can harness the collective intellectual capital that exists within the dispersed employees of organisations.

Design/methodology/approach: This qualitative study explored how shared leadership can be facilitated in internationally dispersed non-formal teams through increased team connectedness, leader humility, empowering leadership, participative leadership and quality leader-member exchanges. The study explored the perspectives of 12 purposively sampled internationally dispersed team members, who represented three different functional nonformal teams.

Findings/results: As dispersion of teams increases, some traditional leadership approaches become less effective. Shared leadership, however, has greater effects on team performance when team dispersion increases.

Practical implications: The study offers a theoretical framework of leadership in internationally dispersed non-formal teams, which serves as a basis for future empirical research. It provides leaders of teams and organisations, as well as human resource practitioners with guidance on how to achieve the benefits of shared leadership of teams in this context. Participants represented nine nationalities, dispersed across eight countries, on four continents.

Originality/value: Studies into shared leadership have increased over the past decade; however, the antecedents that facilitate shared leadership are still not exhaustive, and the majority of studies have been in co-located and formal teams. This study provides insight into how non-formal leaders can facilitate the emergence of shared leadership in the context of dispersed, non-formal teams.

Keywords: organisational complexity; shared leadership; internationally dispersed teams; non-formal teams; organisational structure.

\section{Introduction}

\section{Problem statement}

As globalisation and the complexity of organisations increase, organisations are required to exploit the collective knowledge and leadership that rests within their business to remain competitive (Hoegl \& Muethel 2016; Sweeney, Clarke \& Higgs, 2019). One approach to achieve this is through the establishment of internationally dispersed non-formal teams. The dynamics between formal leaders of co-located teams is different from that of non-formal leaders of geographically dispersed non-formal teams. Moreover, traditional leadership approaches become less effective when dispersion and cultural differences increase (D'Innocenzo, Mathieu, \& Kukenberger, 2016; Sweeney et al., 2019). Shared leadership in the form of mutual horizontal influence has been found to improve outcomes of dispersed teams. However, even though the outcomes are known, current research does not provide sufficient insight into how non-formal leaders can facilitate the emergence of shared leadership in this context.

The purpose of this study was to explore what the leadership behaviours of non-formal leaders are, which facilitate the emergence of shared leadership between the members of geographically dispersed non-formal teams. It informs a framework of non-formal leadership in dispersed work teams and thus contributes to the body of knowledge on shared leadership emergence in dispersed teams. 


\section{Problem context}

Globalisation is making it increasingly challenging for individual leaders to obtain the necessary knowledge, skills and experience to lead teams of knowledge workers through vertical leadership approaches (D'Innocenzo et al., 2016). Multi-national organisations are increasingly deploying horizontal structures, where employees are part of formal colocated work teams, in addition to being part of geographically dispersed non-formal projects or functional teams (Hoch \& Dulebohn, 2017). Furthermore, traditional hierarchical reporting structures are changing, with centralised leaders who are required to influence outcomes of dispersed teams without formal authority through reporting structures (Chiu, Owens, \& Tesluk, 2016).

The purpose of these non-formal teams is to harness the collective knowledge and experience of their members towards defining more nuanced and informed strategies, increased functional innovation and duplicate best practices. Even though these non-formal teams do not have formal reporting structures, the responsibility of team outcomes often rests with a non-formal leader such as a 'regional marketing manager'. In this context, a leader needs to influence team outcomes without formal reporting structures whilst concurrently dealing with the complexities of geographic dispersion (most often international).

Traditional vertical leadership approaches, such as empowering leadership, transactional leadership and directive leadership, rely on the notion that there is some level of formal hierarchy or reporting structure (D'Innocenzo et al., 2016). This suggests that the leaders directly influence in a downwards direction onto the followers (D'Innocenzo et al., 2016). These forms of leadership will not provide sufficient guidance for leaders who need to influence laterally in a context where there is no formal reporting structure. As the complexity of organisations increases, and more leadership capacity is required to remain competitive (Hoegl \& Muethel, 2016), there is an opportunity and a need for organisations to deploy the leadership capabilities that rest within team members beyond formal leaders to increase the organisation's capability to exploit opportunities (Sweeney et al., 2019).

\section{Need for the research}

Zhu, Liao, Yam and Johnson (2018) conducted a review of the research on shared leadership and identified antecedents related to the formal team leader, which include several vertical leadership approaches such as empowering leadership, transformational leadership and leader-member-exchange. All these vertical forms of leadership have been identified as less effective in dispersed teams (Eisenberg, Post, \& DiTomaso, 2019; Hoch \& Kozlowski, 2014; Hoegl \& Muethel, 2016) and are built on the premise of formal authority or hierarchy, which is less applicable to non-formal leaders without formal reporting lines. More research is required into the relationships that influence the decisions of team members to share in the leadership process (Sweeney et al.,
2019). These findings support the view that there is a need for further research on shared leadership emergence in dispersed non-formal teams.

\section{Literature review Defining shared leadership}

D'Innocenzo et al. (2016) define shared leadership as follows, 'Shared leadership is an emergent and dynamic team phenomenon whereby leadership roles and influence are distributed among team members' (p. 5). Sweeney et al. (2019) explain that shared leadership in commercial organisations is concerned with informal peer-to-peer influence towards goals achievement, which is typical in horizontal organisational structures.

\section{Measuring shared leadership}

In the context of dispersed and informal teams, led by nonformal leaders (no formal reporting structures), this study looks at the propensity of individual team members to share in the leadership by performing formal leadership functions within the team. It also looks at how this shared leadership propensity is facilitated through the behaviour of the non-formal leaders to which the team members are linked.

This suggests that shared leadership should not be viewed in terms of the aggregate leadership of the team but rather in terms of the amount and quality of influence interactions that happen between individual members of the team ( $\mathrm{Wu} \&$ Cormican, 2016). Zhu et al. (2018) also explained that by taking a social network approach, the antecedents and outcomes of shared leadership can be studied at the individual level, as it looks at the individual connections between different members of the team.

\section{Shared leadership and improved team outcomes Shared leadership and team performance}

Nicolaides et al. (2014) looked at vertical leadership and shared leadership independently and found that their influence on team performance was similar; however, they found that when they are combined, shared leadership supports an incremental increase of performance outcomes in addition to the effects of vertical leadership. This finding provides promising insight into informal dispersed teams, whose members are in most cases exposed to both vertical and horizontal forms of leadership influence that come from a formally assigned hierarchical leader that is often located close to the team members, as well as a non-formal leader of the informal dispersed team.

\section{Shared leadership and common goal orientation}

Nederveen Pieterse et al. (2019) studied the effects of common goal orientation on teams where there is low authority differentiation and found that it is necessary for these teams to 
have a common goal orientation. These findings are based on the view that if members have different perspectives as to what the goal is, their efforts and strategies will not be aligned, leading to wasted energy that could be applied towards sharing and discussing information, perspectives and ideas that support task execution (Nederveen Pieterse et al., 2019; Nordbäck \& Espinosa, 2019). In internationally dispersed non-formal teams, the authority that rests with the leader differs between teams based on the specific context and based on the perception of hierarchy that the team members are the non-formal leader. It can, however, be argued that there is lower authority differentiation between the members of the non-formal teams and the non-formal leader compared to teams where there are formal reporting structures in place.

\section{Coordination of leadership}

In a recent study conducted in the context of globally dispersed virtual teams, Nordbäck and Espinosa (2019) found that for shared leadership to be effective in this context, there must be explicit coordination of the shared leadership behaviours and activities that are undertaken in the team. Their findings indicate that if the shared leadership activities are not formally coordinated in this context, it could lead to shared leadership having a detrimental impact on team performance as members are potentially being 'led' away from overarching team objectives (Nordbäck \& Espinosa, 2019).

\section{Harnessing collective knowledge for creativity}

The ability to harness the collective knowledge of team members with diverse perspectives is one of the main reasons driving the establishment of internationally dispersed teams (Hoegl \& Muethel, 2016). Vandavasi, McConville, Uen and Yepuru (2020) found that when members of a team engage in acts of knowledge sharing, team innovation is likely to increase. They further identified that shared leadership mediates the positive impact of knowledge sharing on innovation behaviour (Vandavasi et al., 2020), providing support for the positive effects and importance of shared leadership on team and individual-level innovation.

\section{Trust}

The results from a study conducted recently by Klasmeier and Rowold (2020) showed that through building trust, and by applying transformational leadership, organisations could increase shared leadership emergence. In another study conducted by Lyndon, Pande and Navare (2020), cognitive trust was found to support the emergence of shared leadership in teams. Seshadri and Elangovan (2019) emphasise the importance of building trust in globally dispersed teams to support sharing of information between members and to achieve increased performance. The importance of trust between members of dispersed (virtual) teams is emphasised by Breuer, Hüffmeier and Hertel (2016), who found that trust has a positive influence on team performance, with this positive influence being more pronounced in virtual teams than in physical teams.

\section{Team virtuality and connectedness}

Virtuality and high dispersion are defined in terms of the extent to which members are located in different geographic locations, interactions that are primarily facilitated through electronic (virtual) means, culture and nationalities are different and time zones are different (Eisenberg et al., 2019; Hoch \& Dulebohn, 2017). Zhu et al. (2018) explain that team virtuality and team connectedness positively moderate the outcomes of shared leadership. Furthermore, elements like shared mental models, team trust, team cohesion, team consensus, information sharing and coordination of roles serve as mediators between shared leadership and performance, creative and attitudinal outcomes (Zhu et al., 2018). For geographically dispersed teams, the predominantly digital interactions between team members suggest a high level of virtuality, which supports the use of shared leadership in this context. Members of dispersed teams often experience different environmental contexts such as different societal cultures and norms, which creates barriers to understanding and trusting each other, resulting in ineffective communication and collaboration (Eisenberg et al., 2019).

\section{Antecedents of shared leadership}

In a meta-analysis conducted by Sweeney et al. (2019), the antecedents of shared leadership in commercial organisations are discussed under a number of team-related themes, which include characteristics of the individual team members, the composition of the team, the internal environment (Serban \& Roberts, 2016) and external team environment.

\section{Individual characteristics}

Individual team member characteristics that support shared leadership emergence include integrity, commitment, conscientiousness and an eagerness to learn and gain new experiences (Sweeney et al., 2019). In terms of dispersed nonformal teams, the influence of the non-formal leaders on individual characteristics is limited in the short-to-mediumterm. In the medium-to-long-term, this potentially could be influenced through development programmes, sourcing and selection processes.

\section{Team composition and characteristics}

Team composition factors that support shared leadership emergence include higher numbers of female team members, lower average age of the team members and increased national diversity (Sweeney et al., 2019). Hoch and Dulebohn (2017) reviewed the literature on team personality composition and shared leadership in virtual teams and propose that the top five personality traits (emotional stability, agreeableness, extraversion, conscientiousness and openness) at the team level (team personality) are positively related to shared leadership emergence.

\section{The conflict between commonality and diversity}

Drescher and Garbers (2016) indicate that shared leadership emergence and its outcomes are supported by the commonality of team members, as commonality encourages ongoing 
interactions and communication between team members where knowledge is shared and where leadership can be exchanged. Highly diverse internationally dispersed teams could have challenges with developing a feeling of commonality.

The functional diversity (such as differences in perspectives or experiences) that was found to support shared leadership emergence (Kukenberger \& D'Innocenzo, 2020) could reduce the perception of a collective identity for teams in this context, who might feel that their context is so different from the rest of the team that they cannot relate. A collective identity shared between the members of the team enables collective leadership to emerge, whilst incongruence of the values of different team members reduces team members' participation in team activity (Drescher \& Garbers, 2016).

\section{Leadership approaches}

\section{Leader humility}

Even in a formal leadership context, conventional leadership approaches that aim to exert direct influence over team members towards outcomes are less ineffective when members become dispersed (Hoegl \& Muethel, 2016). Chiu et al. (2016) and Zhu et al. (2018) found that, in the context of a formally assigned leader, high leader humility positively influences shared leadership within a team, whilst this relationship is strengthened by the proactive personality of team members.

\section{Participative leadership}

Sweeney et al. (2019) identified participative leadership behaviour, which is associated with empowerment, as an antecedent of shared leadership. Nicolaides et al. (2014) explained that if team members engage in shared leadership, information is shared more freely and member participation increases, which improves team effectiveness and commitment. As dispersed informal team members also have other responsibilities towards their formal co-located teams, their participation in informal team activities could be limited, depriving the team of possible valuable information and contributions. This supports the view that shared leadership could be a feasible alternative leadership approach in this context.

\section{Empowering leadership}

Empowering formal leader behaviour, such as providing members autonomy and authority to act and take decisions, encouraging within-team information exchange and providing freedom of expression, would encourage more team members to exert influence over team outcomes (Oedzes, Rink, Walter, \& Van Der Vegt, 2019), and support shared leadership. Several authors who found that vertical empowering leadership (Fausing, Joensson, Lewandowski, \& Bligh, 2015; Sweeney et al., 2019; Zhu et al., 2018) and psychological empowerment (Grille, Schulte, \& Kauffeld, 2015) increase the probability of shared leadership emergence support this notion.

\section{Exchange}

'Transformational leadership, coaching, and quality leadermember exchanges' are formal leader factors that serve as antecedents for shared leadership (Zhu et al., 2018). The concept of shared leadership is embedded in the notion that influence exchanges and network creation between team members happen during interactions and engagements (Chiu et al., 2016; Song, Gu, \& Cooke, 2020). Dispersed team performance is significantly influenced by effective communication, with unprompted informal communication specifically supporting team effectiveness (Eisenberg et al., 2019). If team members and formal leaders engaged in high quality leader-member exchanges, the team members are more likely to take on a leadership role in informal contexts (Zhu et al., 2018).

\section{Conclusion}

It has been established and is well supported that existing research does not fully describe the antecedents of shared leadership (Chiu et al., 2016; Fausing et al., 2015; Hoch \& Kozlowski, 2014; Muethel, Gehrlein, \& Hoegl, 2012; Serban \& Roberts, 2016; Zhu et al., 2018). None of the studies explore leadership behaviour that facilitates shared leadership emergence from the perspective of the team members, and studies of the antecedents of shared leadership in the specific context of geographically dispersed teams are sparse. Furthermore, these studies consider formally appointed leaders of teams, and do not consider informal leadership structures.

'Current research does thus not provide sufficient insight into what non-formal leaders can do to facilitate the emergence of shared leadership in the context of internationally dispersed non-formal teams'. This study explores qualitatively how shared leadership can be facilitated through the increase of network density in internationally dispersed non-formal teams, by taking a combined approach of, increasing team connectedness, participative leadership, empowering leadership, leader humility and through high quality exchanges.

\section{Methodology}

A multi-case analysis strategy consisting of several teams within one organisation was followed for this study. Creswell, Hanson, Clark Plano and Morales (2007) explain that a case study strategy is appropriate when research attempts to provide an in-depth descriptive account of a phenomenon, where the context of a case can provide particular insight (Yazan, 2015). Eisenhardt (1989) proposes that it is suitable for studying new topic areas, and for application at different levels of analysis, allowing for exploration from different perspectives. This strategy was deemed appropriate for this study as the different perspectives obtained from multiple cases bound by its specific context provided an opportunity to gain heuristic (Creswell et al., 2007; Yazan, 2015) insight into leadership behaviour that facilitates shared leadership of dispersed nonformal team members, from multiple perspectives. 


\section{Research questions}

The following research questions intend to expand our understanding of shared leadership emergence in dispersed non-formal teams.

\section{Research question 1: (Team connectedness)}

What non-formal leader behaviours support increased connectedness between dispersed non-formal team members?

To answer this question, the researchers explored what team members perceive as non-formal leader behaviours that facilitate; 'the creation of connections between team members; improved team trust; a feeling of being a collective; increased team voice; and the willingness to influence team decisions' (Sweeney et al., 2019; Zhu et al., 2018). Answering this question provides guidance to leaders on how to narrow the 'perceived distance' between dispersed non-formal team members to facilitate the emergence of shared leadership.

\section{Research question 2: (Leadership approach)}

How do team members of dispersed non-formal teams perceive and react to non-formal leader humility, empowering behaviour and participative leadership by the non-formal leader?

The researchers explored how team members' perception of non-formal leader humility influences their willingness to share in the leadership of the team (Chiu et al., 2016; Zhu et al., 2018). The role that empowering behaviour and participative leadership play in influencing the team members towards shared leadership was also explored (Fausing et al., 2015; Sweeney et al., 2019; Zhu et al., 2018). Each construct was studied individually in this research, as the literature suggests that these leadership approaches individually support shared leadership emergence in other contexts. Answering this question provides practical guidance to leaders about what appropriate leadership styles are to deploy in this leadership context.

\section{Research question 3: (Quality exchanges)}

What type of exchange behaviour will facilitate shared leadership emergence in dispersed non-formal teams?

To answer this question, the researchers explored the nature of leader-member-exchanges between team members and the non-formal leader that supports the propensity of team members to exert leadership and to identify what the most appropriate and effective means of exchange for shared leadership is to be achieved (Hoch \& Kozlowski, 2014; Zhu et al., 2018). Answering this question provides practical guidance to leaders on how to manage exchanges with nonformal dispersed team members to facilitate shared leadership.

\section{Population}

The population of interest was non-formal leaders of dispersed non-formal work or project teams, typically found in multinational organisations with horizontal structures. The study was done in one large multi-national organisation operating in over 120 countries globally. This organisation makes use of a mix of vertical and horizontal structures. Each country has formal vertical leadership structures, whilst it deploys less formal matrix structures to drive segment and business unit strategies and projects beyond the boundaries of individual countries. The specific population studied consisted of leaders of non-formal team members who are geographically dispersed across Africa, the Middle East, Europe, Asia and North America. Each team represented a single case within the organisation that represented the over-arching case. There are no formal reporting relationships between these strategy leaders and the dispersed team members. However, they have formal leadership responsibility for their respective segments or business units. By selecting multiple cases to explore the single issue (leadership behaviour that facilitates shared leadership in dispersed non-formal teams), it was possible to gain different perspectives on the issue from each case (Creswell et al., 2007). Given that the organisation being studied operates in many countries and that the population for this research was widely dispersed, the findings are likely to be applicable to other realities and settings.

\section{Sampling method and size}

The sampling method was non-probability purposive sampling. Purposive sampling was required as the sampling was done before the start of data collection (Yazan, 2015). For the interviews to provide information-rich data to answer the research questions, the participants were selected based on distinct characteristics (Etikan, Musa, \& Alkassim, 2016; Guest, Bunce, \& Johnson, 2006; Morrow, 2005; Morse, Barret, Mayan, Olson, \& Spiers, 2002).

Characteristics of the sampled team members included:

- They are responsible for executing and implementing strategic priorities defined by the non-formal leaders (ensures task interdependency between leaders and team members: Fausing et al., 2015).

- They are in a different country relative to the strategic leader of their business unit or segment (ensures geographic dispersion).

- They have no formal reporting line to the strategic leader of the segment or business unit (ensures no formal hierarchical authority).

Characteristics of the leaders included:

- They are formally responsible for the individual business units or segments that the sampled team members work in (ensures a link between the leader and team member, to link multiple perspectives to one relationship).

- The team leader and team member tenures in current nonformal teams overlap by more than 12 months (ensures that sufficient time has passed to allow for interaction between individual team members and leaders).

The different functional areas represented by the non-formal leaders and team members included marketing management, 
human resource management and engineering management. Interviews were conducted with four members (three team members and one non-formal leader) of each team with a total number of 12 interviews conducted (Guest et al., 2006; Morrow, 2005) as data neared saturation (Morse et al., 2002).

\section{Data gathering process}

The measurement instrument for this study was semistructured interviews. Each semi-structured interview was recorded electronically after obtaining consent from the respondents to do so (Bhattacherjee, 2012). Each interview was transcribed into text for analysis and for evidence of reliability and accuracy (Bhattacherjee, 2012; Roulston, 2010). Data gathering and analysis were done concurrently, which allowed the researchers to adapt the interview process, style and questions to support the exploration of emerging themes and the discovery of rich nuanced data to answer the research questions (Bhattacherjee, 2012; Morse et al., 2002; Yazan, 2015).

\section{Analysis approach}

The case analysis was done through subjective analysis (Bhattacherjee, 2012), direct interpretation, thematic analysis and categorical aggregation of the case data to identify the emerging themes and constructs (Yazan, 2015). These themes and constructs were then combined into a generalisable and overarching set of constructs (Bhattacherjee, 2012). The first step in the process was to identify individual concepts (units of meaning) from the interview data and to assign each of the different concepts a descriptive code (Corley \& Gioia, 2004). These codes were then studied to identify relationships, which allowed the grouping of the codes into higher order themes (Corley \& Gioia, 2004). The themes were then aggregated together to define a set of overarching constructs for each research question (Bhattacherjee, 2012; Corley \& Gioia, 2004).

\section{Ethical considerations}

Ethical clearance was obtained from the Gordon Institute of Business Science, Ethical Clearance Supervisor Notification.

\section{Results}

\section{Discussion of research question 1 (Connectedness)}

Research question 1: What non-formal leader behaviours support increased connectedness between dispersed non-formal team members?

By answering the research question of 'how connectedness can be increased between internationally dispersed nonformal team members', this study helps us gain understanding of how to facilitate shared leadership emergence in this specific context. Connectedness directly influences network density as it increases the number of influence interactions between the members of the team. This question builds on Zhu et al. (2018), who identified that team connectedness moderates the effects of shared leadership on team performance outcomes, team cohesion moderates the effects of shared leadership on team performance outcomes and team collectivism is an antecedent of shared leadership.

\section{Leader influence on connectedness}

Common goal orientation: The results of this study suggest that non-formal leaders have a core role to play in increasing the connectedness of non-formal internationally dispersed teams. Participants noted that the leader should provide the team with clear direction and a common goal to pursue, which increases connectedness. The interviews noted that the goal should be aligned with the objectives and expectations of the members of the team and other related stakeholders such as their formal leaders, and that these expectations should be formalised by contracting between stakeholders. The findings are supported by other studies that identified that $a$ shared vision and common purpose serve as antecedents of shared leadership (Hoegl \& Muethel, 2016; Nordbäck \& Espinosa, 2019; Sweeney et al., 2019; Zhu et al., 2018).

Development partner: The interviewees pointed out that the leader should act as a development partner by understanding the goals and ambitions of team members, providing constructive feedback and allowing space for failure and learning. The influence of the leader as a development partner did not emerge from the literature reviewed, suggesting a possible novel area for further exploration.

Trust builder: The members of non-formal teams who were interviewed advocated that the non-formal leaders should be deliberate about building trust by taking structured action, actively displaying trust and displaying and encouraging openness. The importance of trust is supported by several authors who identified trust as an antecedent of shared leadership (Klasmeier \& Rowold, 2020; Lyndon et al., 2020; Seshadri \& Elangovan, 2019; Sweeney et al., 2019; Zhu et al., 2018).

Facilitate participation: This study found that the leader can influence connectedness by encouraging and facilitating team participation, and by allowing participative decision-making towards collective and inclusive outcomes. It was also mentioned by interviewees that the leader should aim for majority buy-in to decisions, as opposed to perfect solutions, to support connectedness. The results further suggest that the leader must balance participation with facilitation to prevent unconstructive discussion, and members should be held accountable for their inputs to support the quality of input. Previous studies identified that participative leadership (Sweeney et al., 2019) and participative decision-making (Wu, Cormican, \& Chen, 2020) are antecedents of shared leadership in co-located teams.

Coordinate strengths: The non-formal leader should play the role of coordinator of strengths. The leader is expected to understand the strengths and weaknesses of the different team members and to use this understanding to assign leadership, ownership and decision-making authority for tasks based on 
strengths. This coordination of strengths supports member confidence and participation. The participants further voiced their expectation that the leader should connect members in smaller groups to match strengths of some with the development areas of others to facilitate peer-to-peer coaching. The results provide deeper insights into what the non-formal leader can do to coordinate the leadership activities in the team to prevent uncontrolled leadership that does not support team outcomes as described by Nordbäck and Espinosa (2019) and further allows the legitimisation of leaders that emerge in the team.

\section{Members' influence on connectedness}

Trust and respect: This study found that in addition to the non-formal leader, the members of the team have a role to play in increasing team connectedness. Team members should show trust and respect for each other by getting to know each other, by accommodating cultural differences and by being transparent about their strengths and weaknesses. This team behaviour will support a positive team environment where members can contribute and engage openly without fear. These findings are supported by various authors who identified that trust supports shared leadership emergence (Klasmeier \& Rowold, 2020; Lyndon et al., 2020) and team performance in dispersed teams (Breuer et al., 2016; De Jong, Dirks, \& Gillespie, 2016).

Proactive engagement: The findings show that members should proactively engage with one another on topics of mutual interest without the leader's initiation. It further identifies the need for the members of the team to co-create through collaboration and the sharing of learnings and experiences. This type of cooperative engagement supports the emergence of shared leadership as it allows individual team members to share their diverse functional perspectives with the team (Kukenberger \& D’Innocenzo, 2020).

\section{Contextual influences}

Considering the contextual specificity of the study, it was expected that contextual influences would emerge. The study found that the context of the formal and non-formal team, as well as the commonalities between team members, influence the connectedness of the team.

Formal team: Participants discussed how their day-to-day operations and their formal team needs are prioritised over the non-formal team, which results in reduced commitment and connectedness if the objectives of the two teams are not aligned. Hoegl and Muethel (2016) identified these conflicts of interests as barriers to shared leadership, supporting the finding that objectives between the formal and non-formal teams need to be aligned.

Non-formal team: The findings of this study show that the non-formal team members need to have a voice, be able to influence team decisions and must understand where they fit in the team to increase connectedness. This view is supported by Kukenberger and D'Innocenzo (2020) who found that the functional diversity of team members can only be harnessed if the diversity is valued and included.

Commonality: One of the most significant influencers of connectedness found by this study was 'commonality between team members' in the form of a shared history, shared values and common interests. The participants of one of the teams interviewed had a shared working history of more than a decade. This team emphasised how their history and shared values create a deep connection and in turn enable active practice of shared leadership. Drescher and Garbers (2016), who highlight that a collective identity in the team supports collective leadership emergence, support this finding.

Informality: The influence of informal exchanges on connectedness could not be over emphasised by participants. Less formal exchanges were found to increase connectedness by increasing the frequency of exchange and supporting ongoing conversation. Participants also shared how less formal exchanges help members to get to know each other, build relationships and increase personal connection. Informal and unprompted communication between dispersed team members was found in a previous study to increase team effectiveness (Eisenberg et al., 2019).

Frequency: The results from this study propose that a 'high frequency of relevant, efficient, purposeful, and bi-directional exchanges' significantly increases connectedness between non-formal dispersed team members. Using the frequency and quality of influence interactions between individuals in a team, as a measurement of shared leadership, results in an increased correlation between shared leadership and its positive outcomes (D’Innocenzo et al., 2016).

\section{Research question 2: (Leadership approach)}

Research question 2: How do team members of dispersed non-formal teams perceive humility, empowering behaviour and participative leadership by the non-formal leader?

The significant contextual differences that exist 'between colocated formal teams and internationally dispersed nonformal teams' raise the question of whether leadership approaches that are effective in the one context have the same impact in the other. As leader humility (Chiu et al., 2016; Zhu et al., 2018), empowering leadership and participative leadership (Fausing et al., 2015; Sweeney et al., 2019; Zhu et al., 2018) have already been identified as antecedents of shared leadership, research question two explored how the members of non-formal dispersed teams perceive humility, empowering behaviour and participative leadership by the nonformal leader. In so doing, this question provides an understanding of possible effective leadership approaches that can be applied in this context to facilitate shared leadership emergence. 


\section{Non-formal leader humility}

Members of non-formal dispersed teams consistently described non-formal leader humility as a highly appreciated leadership trait for a non-formal leader in this context.

Perception of the humble leader: Several participants shared the view that non-formal leader humility supports the perception of the leader being genuine and human, which makes the leader more relatable to the team. Participants commented that there are often unrealistic expectations placed on the leader because of perceived hierarchy and felt that humility helps to rationalise these expectations. These findings further suggest that humility will reduce authority differentiation and increase the propensity of team members to engage in leadership behaviour (Nederveen Pieterse et al., 2019).

Expectations of the humble leader: The responses from participants indicated that there are two over-arching expectations of the humble leader in this context. The first expectation is that the leader should be a facilitator of team inputs by listening to the team, bringing together the inputs of the team and not forcing decisions top-down. This construct is linked to the findings of research question one, where it was noted that the leader should facilitate participation that is an antecedent of shared leadership (Sweeney et al., 2019; Wu et al., 2020).

The second expectation that emerged from the results is that the leader must align the team towards a goal by sharing the 'big picture' and by helping the team to understand the benefits for them. This finding is also linked to research question one and is supported by several authors who define various iterations of common goal orientation that are important for shared leadership in teams (Hoegl \& Muethel, 2016; Nederveen Pieterse et al., 2019; Nordbäck \& Espinosa, 2019; Seshadri \& Elangovan, 2019; Sweeney et al., 2019; Wu et al., 2020; Zhu et al., 2018).

Limitations of non-formal leader humility: The majority of the participants interviewed in this study acknowledge that there are certain limitations to humility that the non-formal leader should consider. The findings show that the leader is often required to show lower levels of humility to manage team dynamics such as unconstructive exchanges or to prevent endless discussions that lead nowhere. The data collected suggest that there is a risk that humility can be perceived as weakness if the leader is unable to identify and adapt to situations where humility is not appropriate. The analysis of the responses of participants shows that non-formal leader humility is overwhelmingly positive but must be balanced to overcome its limitations.

\section{Empowering leadership}

As previously discussed, vertical empowering leadership has been identified as an antecedent of shared leadership in formal and co-located teams (Fausing et al., 2015; Sweeney et al., 2019; Zhu et al., 2018). The results discussed in this section extend the construct of practicing empowering leadership to the context of internationally dispersed non-formal teams to support shared leadership emergence.

It was identified during the analysis of the interviews that there are specific non-formal leader behaviours that are perceived as empowering, by internationally dispersed non-formal teams.

Align the team towards a common goal: Participant responses show that the leader must empower the team by aligning them towards a common goal. Interviewees indicated that this can be achieved by explaining the 'reasons why', showing members 'what is in it for them' and by connecting the 'day-to-day' to the 'big picture'. The results show that members feel un-empowered when they feel that their context is different or when their individual needs are not acknowledged. This places significant emphasis on this reoccurring theme of a shared vision and common purpose, which was identified in the literature as an antecedent of shared leadership (Hoegl \& Muethel, 2016; Nederveen Pieterse et al., 2019; Nordbäck \& Espinosa, 2019; Seshadri \& Elangovan, 2019; Sweeney et al., 2019; Wu et al., 2020; Zhu et al., 2018).

Trust the team: The results established that team members feel empowered when they are trusted by the non-formal leader. One of the participants emphasised that the non-formal leader must be able to 'let go of the reigns' and trust in the ability of the team for them to be empowered. This concept of trust refers to the trust displayed by the leader towards the team, which is linked to leader humility where trust was identified as an outcome.

Hold members accountable: The responses from participants proposed that 'accountability is empowering'. The results show that the leader must hold team members accountable for their contributions to the team and the execution of their assigned responsibilities for them to be empowered. The leader must also provide direct feedback when the leader feels that something needs to change. The literature reviewed did not reveal much insight into accountability associated with shared leadership, which could be an avenue for future research.

Strengths-based ownership: Strengths-based ownership requires the leader to understand the strengths and weakness of team members and using that understanding to distribute ownership amongst the members based on their strengths and competencies. The distribution of task leadership was found to enable shared leadership (Hoegl \& Muethel, 2016). Grille et al., (2015), who identified psychological empowerment as an antecedent of shared leadership, supports these findings that the distribution should be based on strengths. The findings further provide insight into how the leadership activities of internationally dispersed nonformal teams can be coordinated by the non-formal leader to support the perception of personal and peer leadership legitimacy in the team (Nordbäck \& Espinosa, 2019), which will encourage mutual leadership and followership in the team. 
Freedom of choice: It was further found that to empower team members, they must be given the freedom to choose the tasks or topics they lead or get involved with, which facilitates alignment with strengths and interests supporting greater commitment. This also links directly to the literature on psychological empowerment (Grille et al., 2015) and personal and peer leadership legitimacy (Nordbäck \& Espinosa, 2019).

Team members make decisions: The leader should empower members to make decisions and do this by sharing information, allowing functional experts and topic owners to make decisions and by not scrutinising member decisions unless there are fundamental concerns. The leader must allow space for failure and learning and should allow the team to take credit for team outputs in the broader organisation. The literature supports the view that team members should be given enough autonomy to influence and take decisions to encourage rather than undermine shared leadership (Hoegl \& Muethel, 2016; Oedzes et al., 2019).

\section{Participative leadership}

Participative leadership is an antecedent of shared leadership (Sweeney et al., 2019). The interviews probed how to approach participative leadership in internationally dispersed non-formal teams and the elements that influence team participation in this context.

Participation from strengths: The interviews confirmed that participation and involvement of team members should be expected in areas where they have competencies and strengths. This requires that the leader understands the strengths of the team and that ownership should be aligned with strengths. Based on the context of members being in formal and nonformal teams concurrently, it was found that the leader should adjust participation expectations to align with what is manageable for members.

Extracts and syntheses: Participants see the non-formal leader as the one who extracts and synthesises the inputs of the team. The leader was described as the one who keeps the 'big picture' in mind whilst extracting inputs from all team members before bringing those inputs together. The literature supports these findings by proposing that functional diversity can only support shared leadership emergence if the team members' diverse perspectives can be extracted through participation (Kukenberger \& D'Innocenzo, 2020).

Participative decision-making: Based on the findings, the leader is expected to facilitate participative decision-making and to keep their opinions for when it is critical. The leader is also responsible for moderating a safe team environment where members are respected, and contributions are valued. Literature supports these findings by pointing out that a collaborative environment, where members can participate and have a voice, supports shared leadership emergence (Drescher \& Garbers, 2016; Hoegl \& Muethel, 2016).

Individual team member influence: The analysis shows that personality and experience significantly influence participation with some individuals being more comfortable to participate than others. It was also found that team members have different expectations in order to participate, with some expecting time to prepare and a detailed description of expectations, whilst others are comfortable to participate without prior notice.

Contextual influences: One leader emphasised the importance of having competent team members before participative leadership is applied. Trust and humility are believed to support constructive debate between team members and support participation. Members of the non-formal team want to understand 'where they fit and what role they play' in the team before they participate. The last contextual influence identified from the results is a hierarchical company culture that hinders non-formal team decision-making. These findings are consistent with those of De Jong et al. (2016), who highlighted the positive effects participation has on performance based on trust in the team.

\section{Discussion of research question 3 (Quality exchanges)}

\section{Research question 3: What type of exchange behaviour will facilitate shared leadership emergence in dispersed non-formal teams?}

Members of internationally dispersed teams face obvious practical challenges when attempting to engage in quality exchanges with their fellow-team members. The literature supports the view that high-quality leader-member exchanges become more difficult to facilitate as dispersion increases (Hoch \& Kozlowski, 2014; Seshadri \& Elangovan, 2019). The discussion of the findings of the third research question builds on the premise that high-quality exchanges between the leader and the team members increase members' inclination to engage in leadership behaviour (Zhu et al., 2018). It also supports the idea that the number and quality of leadership exchanges between individuals define shared leadership strength (Wu \& Cormican, 2016). It does this by providing a rich account of how the non-formal leader can facilitate high quality exchanges with team members in this dispersed context.

\section{Types of exchanges}

When participants were asked about what they experience as a quality leader-member exchange, the majority referred to the distinction that needs to be made between 'formal and informal exchanges'. Most participants felt that their nonformal dispersed teams predominantly engage in formal exchanges done within a fixed schedule and with set agendas where 'general best practice' for running meetings should apply. Participants added that quality can be increased by introducing a balance between formal and informal exchanges.

\section{Informal exchanges}

The interviews revealed that members of non-formal dispersed teams feel that less formal exchanges are generally of 
higher quality, and that formal exchanges should have elements of informality to increase the quality. This can be linked to the findings of Eisenberg et al. (2019).

Participants shared how they see less formal exchanges as a means of strengthening relationships. Less formal exchanges create opportunities for team members to get to know each other to understand how individuals in the team are feeling, to support openness and to create a feeling of belonging.

The participants repeatedly made the link between the concept of informal exchange and high frequency and defined how this combination increases exchange quality. The results suggest that less formal and frequent exchanges increase pragmatism by encouraging ongoing conversation and increase connectedness by building relationships and reducing perceived distance. Members did highlight that in the specific context, frequent exchanges need to be relevant and efficient for them to maintain their value. Eisenberg et al. (2019) explain that informal unprompted communication supports team effectiveness, which supports these findings.

\section{Mix between virtual and physical}

It is clear from the results that there is consensus that 'physical exchanges are preferred over virtual', and that there is a strong expectation for the leader to arrange physical engagements for non-formal dispersed teams. Physical exchanges emerged as a key element for building relationships and for reducing formality. Seshadri and Elangovan (2019), who found that a lack of physicality increases the time it takes to create trust in dispersed teams, support these findings. Virtual exchanges are perceived as risky, reducing information exchange and constructive engagement (Breuer et al., 2016).

\section{Boundary conditions for quality exchanges}

Certain boundary conditions that need to be met for quality exchanges could be identified from the responses from the interviewed teams. A positive and solutions-oriented mind set and a friendly atmosphere are described as pre-requisites for having quality exchanges with the non-formal leader. The leader must show personal interest in how the person feels, what their strengths and weakness are and what their development goals and ambitions are. The findings emphasise that team members want to be prepared for exchanges, underpinning the importance of making sure that team members know what the expectations and objectives of a particular exchange are.

\section{Trust for quality exchanges}

The concept of trust emerged repeatedly in all three research questions, accentuating its importance in non-formal dispersed team leadership. Within the context of exchange, trust was found to be a key enabler for high-quality engagements.

From the findings, trust and respect support team authenticity as team members are more inclined to be transparent and display their authentic selves. Achieving this trust is supported by leader humility that was discussed under research question two. Trust was further found to increase openness in the team, which in turn strengthens relationships. It was mentioned that a leader who displays openness to feedback from team members encourages openness in the team. Participants further pointed out that members will not show vulnerability if the non-formal leader is not trusted to challenge the team internally whilst defending the team in the broader organisation. The view that trust is needed for members to show vulnerability is supported by De Jong et al. (2016), who highlighted that the willingness to be vulnerable helps to use energy exerted by individuals to protect themselves against harm, more constructively to reach team objectives.

\section{Means of quality exchange}

Interviewees noted that the means of exchange should be aligned with whether the exchange is seen as formal or informal. For quality formal exchanges, the findings suggest that participants cite 'general known best practice' for conducting meetings such as fixed time, a set agenda, clear objectives and efficient execution.

\section{Process of shaping outcomes}

Most of the interviewees referred to elements related to the process of shaping outcomes that influence the quality of exchange. The analysis of the findings proposes that quality increases when outcomes are shaped through personalised engagements where parties collaborate (including within-team exchanges without the non-formal leader), towards inclusive outcomes. Interviewees proposed that exchanges should be personalised by adapting to the cultural differences and the individual needs of team members, as well as providing personal feedback or coaching. Eisenberg et al. (2019) also emphasise the barriers to communication and collaboration that are created by different cultures and norms, supporting the concept of personalised exchanges.

A key element of the process of shaping outcomes in internationally dispersed teams identified from the findings is within-team exchanges. Within the context described, the leader cannot effectively play the 'middle person' between all the exchanges of the team. The results show that the leader should create smaller teams to collaborate on specific tasks. This further indicates that members should individually engage with one another on topics of mutual interest, which will help members build on one another's perspectives. The concept of creating smaller teams is associated with task leadership distribution, which supports shared leadership emergence (Hoegl \& Muethel, 2016).

\section{Outcome expectations}

The first type of outcome that was unanimously associated with a quality exchange is definitive outcomes. These include an agreement between parties, decisions made, actions taken and the impact of outcome. The second type of outcome identified from the results is relevant knowledge sharing. These outcomes include the sharing of ideas, experience and 
knowledge that can be used to address the reality experienced by the team members in the day-to-day context of their work. The importance of knowledge sharing is supported by Kukenberger \& D'Innocenzo (2020), Sweeney et al. (2019) and $\mathrm{Wu} \&$ Cormican (2016). The final type of outcome that emerged from the responses is intangible outcomes. Participants noted that not all outcomes of exchanges need to be tangible, and that intangible outcomes such as getting to know each other, building stronger relationships and increasing trust could also be an outcome of a quality exchange.

\section{Conclusion}

This study addressed the call to action from Sweeney et al. (2019) and various other authors, who noted that the study of the antecedents of shared leadership is needed in a variety of organisational contexts to expand our knowledge of how to facilitate this form of leadership in commercial organisations.

\section{Research question 1: Connectedness}

In this study, connectedness between team members was positioned as a key enabler of increased network density in internationally dispersed non-formal teams, as connectedness beyond the non-formal leader will lead to network decentralisation and will increase the number and strength of influence interactions between the members of the team (Wu \& Cormican, 2016). This will lead to shared leadership based on the finding that network density is a more reliable measurement of shared leadership (D'Innocenzo et al., 2016; Zhu et al., 2018). This study found that to influence connectedness in this context, leaders should consider four overarching influencing factors. These factors are the non-formal leader, the members of the non-formal team, the influence of exchange and the context. The study also found that increased connectedness results in improved team dynamics, empathy, participation and business execution, which would support these teams to achieve their objectives. The study also found direct links between connectedness and the other four constructs explored in this study. These links are facilitated through several mutual concepts between connectedness and the other four constructs, which include the facilitation of participation, the influence of exchange, a common goal orientation, the building of trust, coordination of strengths and the creation of networks.

\section{Research question 2: Leadership approach}

Because of the contextual specificity of internationally dispersed non-formal teams, this study explored the applicability of three leadership approaches that were found to facilitate shared leadership in other contexts. Studies found that as teams become more dispersed, several traditional leadership approaches become less effective (Eisenberg et al., 2019; Hoch \& Kozlowski, 2014). Moreover, the removal of formal reporting lines to the leader brought into question the applicability of these approaches in this context. As such, this study explored how leader humility (Chiu et al., 2016; Zhu et al., 2018), empowering leadership (Sweeney et al., 2019; Zhu et al., 2018) and participative leadership (Sweeney et al., 2019) are perceived in internationally dispersed non-formal teams, and how these approaches can be applied successfully in this specific context to facilitate shared leadership. It was found that all three leadership approaches are positively perceived and encouraged by the members of these teams, and these approaches encourage them to 'step up' and share in the leadership of the team.

\section{Research question 3: Exchange}

Considering the dispersed nature of the teams studied, it is evident that the core of their influence exchanges is predominantly through virtual engagements. These engagements are the key 'vehicles' that facilitate the exchange of influence and leadership between team members, which are at the core of shared leadership (Song et al., 2020). As such, this study explored the nature and means of facilitating high quality exchanges between the members of these teams to understand how to increase their quality and effectiveness. It found that virtual and physical exchanges provide different but complementary benefits to teams in this context. Furthermore, non-formal exchanges were found to significantly increase the ability of team members to engage in leadership and influence behaviours, an outcome that is strengthened by their ability to increase the frequency of exchange. Formal structured exchanges are effective for engaging deeply and focus on a topic, whilst these are less effective for exploring creative and novel ideas. Quality exchanges are individualised to participants and allow collaboration towards outcomes that are inclusive of the views of the different participants. The levels of trust between individuals who engage in an exchange will influence the participants' authenticity and thus the quality. Quality exchanges can have both tangible and intangible outcomes, dependent on the objective of the exchanges, both of which are valuable to teams in this context. Overall, expectations of exchanges should be clear, participants must show personal interest in one another and there must be a friendly solution-oriented mindset. Exchanges are the 'vehicles' through which leaders show humility, encourage participation, empower members and connect individuals.

\section{Implications for management and other relevant stakeholders}

It is evident that organisations are increasing in complexity and that globalisation is challenging organisations to explore alternative leadership approaches to harness their collective intellectual capital to remain competitive. The findings of this study have several implications for leaders of internationally dispersed non-formal teams, as well as for organisations that seek to effectively deploy these types of team structures to exploit the potential commercial benefits. The findings provide practical guidance to leaders on how they can facilitate shared leadership and as a result effectively harness the collective knowledge and experience that rests within their teams. The findings further provide guidance to human resource practitioners and organisational leaders who seek to employ or develop leaders or team members that would be more likely to 
be effective in this context. The findings also give organisations guidance towards possible areas to address through training interventions that can help existing teams (both leaders and team members) to increase their effectiveness. The findings suggest that organisations should consider moderately humble, participative and empowering leaders for these roles, as opposed to the 'great individual leaders' who see themselves as the core of the team. These findings further suggest that organisations should invest in the strengthening of connections by prioritising physical engagements of these dispersed teams and to support them with the necessary tools and resources to have quality exchanges.

\section{Limitations of the research}

Even though the sample of this study included team members from three different functional business areas that do different types of work, it was conducted in one large multinational organisation that operates in the construction and industrial sectors. This could reduce its generalisability to other functional areas, organisation types and industries.

All participants interviewed were already senior leaders in the organisation, which could influence their propensity to engage in leadership behaviours without the influence of the non-formal leader. This could limit the applicability of the findings to more junior teams with members that do not fulfil formal leadership functions.

The participants of this study were highly diverse in terms of nationalities, which resulted in most participants not responding to interview questions in their first language. Even though all participants were proficient in business level English, it is possible that the language barrier could have influenced their ability to express their thoughts and the researchers' ability to interpret the meaning of their responses accurately.

The researcher is an employee of the organisation in which the study was conducted and is also a non-formal leader of internationally dispersed teams. Even though this provides the researcher with personal knowledge and experience of the topic under study, it could have influenced the objectivity of data gathering and interpretation.

\section{Suggestions for future research}

This study found links and interdependencies between the five constructs explored; however, the scope of the study did not allow for further investigation into the nature of these interdependencies. Future empirical research can study these interdependencies in greater detail to further build our understanding of shared leadership in this context.

Future research can take a longitudinal approach to study the impact of these specific leadership interventions over time to further build our understanding of shared leadership emergence in this context.
This study identified a number of boundary conditions that influence the effectiveness of the core constructs, which relate to the team dynamics, member 'fit' in the team, competence, company culture. Future studies can test these constructs empirically as mediators or moderators in the context of internationally dispersed non-formal teams.

Considering that this study was performed in one multinational organisation, and in a specific industry, future studies can be performed in different industries and in different commercial organisations to understand to what extent the findings are congruent across industries and organisational cultures.

Even though exchange is at the core of shared leadership, there are surprisingly few studies that focus on the means of exchange that facilitate shared leadership. Considering the rapid pace of technological advancement and the reality of a 'post-pandemic' world, it is proposed that more research is required to be done into the means of exchange for effective shared leadership.

\section{Acknowledgements Competing interests}

The authors have declared that no competing interest exists.

\section{Authors' contributions}

Mr Van Zyl conducted the research under the supervision of Prof Hofmeyr.

\section{Funding information}

This research received no specific grant from any funding agency in the public, commercial, or not-for-profit sectors.

\section{Data availability}

The data that support the findings of this study are available from the corresponding author, K.H., upon reasonable request.

\section{Disclaimer}

The views and opinions expressed in this article are those of the authors and do not necessarily reflect the official policy or position of any affiliated agency of the authors.

\section{References}

Bhattacherjee, A. (2012). Social science research: Principles, methods, and practices (2nd ed.). Tampa, FL: University of South Florida.

Breuer, C., Hüffmeier, J., \& Hertel, G. (2016). Does trust matter more in virtual teams? A meta-analysis of trust and team effectiveness considering virtuality and documentation as moderators. Journal of Applied Psychology, 101(8), 1151-1177. https://doi.org/10.1037/apl0000113

Chiu, C.Y.C., Owens, B.P., \& Tesluk, P.E. (2016). Initiating and utilizing shared leadership in teams: The role of leader humility, team proactive personality, and team performance capability. Journal of Applied Psychology, 101(12), 1705-1720. https://doi.org/10.1037/apl0000159

Corley, K.G., \& Gioia, D.A. (2004). Identity ambiguity and change in the wake of a corporate spin-off. Administrative Science Quarterly, 49(2), 173-208. https://doi. org/10.2307/4131471 
Creswell, J.W., Hanson, W.E., Clark Plano, V.L., \& Morales, A. (2007). Qualitative research designs: Selection and implementation. The Counseling Psychologist, 35(2), 236-264. https://doi.org/10.1177/0011000006287390

De Jong, B.A., Dirks, K.T., \& Gillespie, N. (2016). Trust and team performance: A metaanalysis of main effects, moderators, and covariates. Journal of Applied Psychology, 101(8), 1134-1150. https://doi.org/10.1037/apl0000110

D'Innocenzo, L., Mathieu, J.E., \& Kukenberger, M.R. (2016). A meta-analysis of different forms of shared leadership-team performance relations. Journal of Management, 42(7), 1964-1991. https://doi.org/10.1037/apl0000110

Drescher, G., \& Garbers, Y. (2016). Shared leadership and commonality: A policy capturing study. The Leadership Quarterly, 27(2), 200-217. https://doi. org/10.1016/j.leaqua.2016.02.002

Eisenberg, J., Post, C., \& DiTomaso, N. (2019). Team dispersion and performance: The role of team communication and transformational leadership. Small Group Research, 50(3), 348-380. https://doi.org/10.1177/1046496419827376

Eisenhardt, K. M. (1989). Building theories from case study research. Academy of Management Review, 14(4), 532-550.

Etikan, I., Musa, S.A., \& Alkassim, R.S. (2016). Comparison of convenience sampling and purposive sampling. American Journal of Theoretical and Applied Statistics, 5(1), 1-4. https://doi.org/10.11648/j.ajtas.20160501.11

Fausing, M.S., Joensson, T.S., Lewandowski, J., \& Bligh, M. (2015). Antecedents of shared leadership: Empowering leadership and interdependence. Leadership \& Organisation Development Journal, 36(3), 271-291. https://doi.org/10.1108/ LODJ-06-2013-0075

Grille, A., Schulte, E.M., \& Kauffeld, S. (2015). Promoting shared leadership: A multilevel analysis investigating the role of prototypical team leader behavior, psychological empowerment, and fair rewards. Journal of Leadership \& Organisational Studies, 22(3), 324-339. https://doi.org/10.1177/1548051815570039

Guest, G., Bunce, A., \& Johnson, L. (2006). How many interviews are enough? An experiment with data saturation and variability. Field Methods, 18(1), 59-82. https://doi.org/10.1177/1525822X05279903

Hoch, J.E., \& Dulebohn, J.H. (2017). Team personality composition, emergen leadership and shared leadership in virtual teams: A theoretical framework. Human Resource Management Review, 27(4), 678-693. https://doi.org/10.1016/j. hrmr.2016.12.012

Hoch, J.E., \& Kozlowski, S.W. (2014). Leading virtual teams: Hierarchical leadership structural supports, and shared team leadership. Journal of Applied Psychology, 99(3), 390-403. https://doi.org/10.1037/a0030264

Hoegl, M., \& Muethel, M. (2016). Enabling shared leadership in virtual project teams: A practitioners' guide. Project Management Journal, 47(1), 7-12. https://doi. org/10.1002/pmj.21564

Klasmeier, K.N., \& Rowold, J. (2020). A multilevel investigation of predictors and outcomes of shared leadership. Journal of Organisational Behavior, 41(9), 915-930. https://doi.org/10.1002/job.2477

Kukenberger, M.R., \& D'Innocenzo, L. (2020). The building blocks of shared leadership: The interactive effects of diversity types, team climate, and time. Personnel Psychology, 73(1), 125-150. https://doi.org/10.1111/peps.12318

Lyndon, S., Pandey, A., \& Navare, A. (2020). Shared leadership and team creativity: Investigating the role of cognitive trust and team learning through mixed method approach. Personnel Review, 49(9), 1805-1822. https://doi.org/10.1108/PR-052019-0262

Morrow, S.L. (2005). Quality and trustworthiness in qualitative research in counselling psychology. Journal of Counseling Psychology, 52(2), 250-260. https://doi. org/10.1037/0022-0167.52.2.250
Morse, J.M., Barrett, M., Mayan, M., Olson, K., \& Spiers, J. (2002). Verification strategies for establishing reliability and validity in qualitative research. International Journal of Qualitative Methods, 1(2), 13-22. https://doi.org/ International Journal of Qualitat

Muethel, M., Gehrlein, S., \& Hoegl, M. (2012). Socio-demographic factors and shared leadership behaviors in dispersed teams: Implications for human resource management. Human Resource Management, 51(4), 525-548. https://doi. org/10.1002/hrm.21488

Nederveen Pieterse, A., Hollenbeck, J.R., Van Knippenberg, D., Spitzmüller, M., Dimotakis, N., Karam, E.P., \& Sleesman, D.J. (2019). Hierarchical leadership versus self-management in teams: Goal orientation diversity as moderator of their relative effectiveness. The Leadership Quarterly, 30(6). https://doi.org/10.1016/j. leaqua.2019.101343

Nicolaides, V.C., LaPort, K.A., Chen, T.R., Tomassetti, A.J., Weis, E.J., Zaccaro, S.J., \& Cortina, J.M. (2014). The shared leadership of teams: A meta-analysis of proximal, distal, and moderating relationships. The Leadership Quarterly, 25(5), 923-942. https://doi.org/10.1016/j.leaqua.2014.06.006

Nordbäck, E.S., \& Espinosa, J.A. (2019). Effective coordination of shared leadership in global virtual teams. Journal of Management Information Systems, 36(1) 321-350. https://doi.org/10.1080/07421222.2018.1558943

Oedzes, J.J., Rink, F.A., Walter, F., \& Van Der Vegt, G.S. (2019). Informal hierarchy and team creativity: The moderating role of empowering leadership. Applied Psychology, 68(1), 3-25. https://doi.org/10.1111/apps.12155

Roulston, K. (2010). Considering quality in qualitative interviewing. Qualitative Research, 10(2), 199-228. https://doi.org/10.1177/1468794109356739

Serban, A., \& Roberts, A.J. (2016). Exploring antecedents and outcomes of shared leadership in a creative context: A mixed-methods approach. The Leadership Quarterly, 27(2), 181-199. https://doi.org/10.1016/j.leaqua.2016.01.009

Seshadri, V., \& Elangovan, N.D. (2019). Role of manager in geographically distributed team: A review. Journal of Management, 6(1), 122-129. https://doi.org/10.34218/ JOM.6.1.2019.013

Song, Z., Gu, Q., \& Cooke, F.L. (2020). The effects of high-involvement work systems and shared leadership on team creativity: A multilevel investigation. Human Resource Management, 59(2), 201-213. https://doi.org/10.1002/ hrm.21988

Sweeney, A., Clarke, N., \& Higgs, M. (2019). Shared leadership in commercial organisations: A systematic review of definitions, theoretical frameworks and organisational outcomes. International Journal of Management Reviews, 21(1) 115-136. https://doi.org/10.1111/ijmr.12181

Vandavasi, R.K.K., McConville, D.C., Uen, J.F., \& Yepuru, P. (2020). Knowledge sharing, shared leadership and innovative behaviour: A cross-level analysis. Internationa Journal of Manpower, 44(8), 1221-1233. https://doi.org/10.1108/IJM-04-20190180

Wu, Q., \& Cormican, K. (2016). Shared leadership and team creativity: A social network analysis in engineering design teams. Journal of Technology Management \& Innovation, 11(2), 2-12. https://doi.org/10.4067/S0718-27242016000200001

Wu, Q., Cormican, K., \& Chen, G. (2020). A meta-analysis of shared leadership: Antecedents, consequences, and moderators. Journal of Leadership \& Organisational Studies, 27(1), 49-64. https://doi.org/10.1177/1548051818820862

Yazan, B. (2015). Three approaches to case study methods in education: Yin, Merriam and Stake. The Qualitative Report, 20(2), 134-152. https://doi.org/10.46743/2160and Stake. The Qu

Zhu, J., Liao, Z., Yam, K.C., \& Johnson, R.E. (2018). Shared leadership: A state-of-the-art review and future research agenda. Journal of Organisational Behavior, 39(7), 834-852. https://doi.org/10.1002/job.2296 